\title{
Bureau's national involvement signifies policy change
}

THE Australian Bureau of Mineral Resources, Geology and Geophysics (BMR) is nearing the end of a transformation of its role in Australian geoscience. A sign of the change is the bureau's involvement in a forthcoming national programme of research into the continental crust, for which proposals were discussed at a recent meeting in Canberra (see p.214).

Following a government decision in 1978, BMR has been changed, broadly speaking, from a survey body into a resource-orientated research organization which, with its continental outlook, will act as a coordinating force for basic, resourcerelated research. Judging by the scope of its research programmes, BMR's nets are to be widely cast over the scientific puzzles posed by the surface and underlying structure of Australasia.

Before its transformation, BMR had been responsible for the geological mapping of Australia at a scale of 1:250,000. In 1978, the Australian Science and Technology Committee (ASTEC) recommended drastic changes and the government agreed. The mapping had been largely completed and, with one of two exceptions (such as the Northern Territory, where support from BMR is still being provided), the maintenance of surveys was transferred to regional bodies. But BMR has been asked that its research, although it might be more fundamental and wider in scope, should have more justification than pure intellectural curiosity. A new director, Dr Roy Rutland, was appointed to carry out the transformation.

The most obvious chanes have been in BMR's structure. The bureau now has divisions concerned with geophysics, continental geology, petrology and geochemistry, marine geoscience and petroleum geology, together with the Bass Becking Laboratory and the Special Projects and Geoscience Services (responsible, among other projects, for Antarctic research). Each subdivision has a newly appointed director, and part of Dr Rutland's achievement has been to persuade the Australian Government that a sufficiently high status and salary should be provided for these and other research posts. Most of the scientific staff before the change were at "experimental officer" level; the reorganization of BMR has resulted in a significant

\section{British Technology Group}

CONTRARY to the suggestion made in Nature last week (10 March, p.100), Dr Richard Flavell has not in fact been offered an appointment with the new agricultural genetics company proposed by the British Technology Group. We apologize for any embarrassment caused. number (70 or so) of posts at the more senior "research scientist" level. Of these, about 45 have been filled by internal promotion.

Although its research must be related to mineral resources, BMR's scientific programme is wide, (as is its primary mandate "to develop an integrated, comprehensive, scientific understanding of the geology of the Australian continent, the Australian offshore area and the Australian Antarctic Territory, as a basis for minerals exploration".

Thus BMR is newly involved, for example, in research into active and passive continental margins (division of marine sciences and petroleum geology) and earthquake seismology and seismic risk (division of geophysics). And a mark of the prominent role to be played by BMR from now on its the chairmanship by Dr Rutland of the LITSAC project (Lithospheric Transect Studies of the Australian Continent) which was discussed at the Canberra meeting, and the chairmanship of the Australian National Committee for the International Lithosphere Project by $\mathrm{Dr}$ Michael McElhinny, director of BMR's division of geophysics.

Inevitably, the transformation of BMR has involved controversy, internal and external. The large amount of "new blood" brought in (particularly at higher levels) created strains within the organization, although these have now been somewhat moderated, partly by early retirements. More visibly, there was disagreement between BMR and the Commonwealth Scientific and Industrial Research Organization (CSIRO) on their future relationship. The situation seems to have been resolved so that CSIRO is to play a tactical role in collaboration with industry on the enhanced exploitation of mineral resources after discovery.

Philip Campbell

\section{Collisions on course to produce shower of charged particles}

High-energy physics

NoT content with the recent discovery of the intermediate vector boson, physicists at CERN, the European Centre for Nuclear Physics near Geneva, intend to double the energy of the collider that produced the bosons and seek a totally different but equally spectacular phenomenon: Centauro events.

Centauros are collisions involving a high-energy cosmic ray and a nucleus in the atmosphere, in which a vast shower of charged particles (around 100) is produced, but almost no neutral ones. Five Centauros have been detected in cosmic ray experiments, but there is no conventional explanation of these events. One possibility is that they represent a phase transition: that they are the sign of the formation and decay of a quark-gluon "gas ball", a gaseous state of the quarks as opposed to the usual "liquid" state of the photon, neutron and other hadrons.

Noting this, John Rushbrooke of the University of Cambridge a year ago proposed an ingenious way of raising the energy of proton-antiproton collisions in the CERN collider so as to match the probable energy of the Centauro cosmic ray collisions - and so reproduce the events in a controlled way in the laboratory. His proposal, made as part of a Bonn-BrusselsCambridge-CERN-Stockholm collaboration, has now been accepted by the CERN scientific programming committee.

The problem limiting the energy of the collider is ohmic (electrical) heating in the bending magnets, which steer stored bunches of protons and antiprotons in opposite directions around the super-proton- synchrotron ring. Fears of overheating have limited proton and antiproton stored beam energy to $270 \mathrm{GeV}$, and thus collision energies to $540 \mathrm{GeV}$. But, Rushbrooke reasoned, if the magnet current could be pushed just briefly higher, and for the remaining time held lower than needed to run beams at $270 \mathrm{GeV}$, it might be possible to accelerate the protons and antiprotons briefly to a higher energy and then drop them down again, keeping the same mean level of heating in the magnets. "It will cost nearly nothing", Rushbrooke says.

This, then, is the accepted proposal: to try out pulsed operation of the collider, with collision energies reaching 800-900 $\mathrm{GeV}$ for perhaps 3 seconds in a cycle lasting 14 seconds. The beam would "rest" between peaks at $100 \mathrm{GeV}$. Experiments should take place in 1984.

The exercise is a gamble, however: a gamble on whether the accelerator can be made to operate in this way without losing too much beam (a loss of 1 per cent per cycle would be just tolerable) and a gamble on whether the energy is right. Rushbrooke estimates that 5-10 per cent of some 30,000 events collected in a few days' operation should be Centauros; but the measurement of cosmic ray event energies is so inaccurate that it is possible that the threshold (minimum energy required) for the Centauros is even higher than Rushbrooke can reach. If so, it will be bad luck; if not, CERN will have beaten the United States to physics which will become available at the $1,800 \mathrm{GeV}$ (centre of mass) collider at Fermilab, near Chicago, only by late 1986 .

Robert Walgate 